\title{
7-day weighed food diaries suggest patients with hereditary hemorrhagic telangiectasia may spontaneously modify their diet to avoid nosebleed precipitants
}

\author{
Helen Finnamore ${ }^{1,3}$, B. Maneesha Silva ${ }^{2}$, B. Mary Hickson ${ }^{4}$, Kevin Whelan ${ }^{3}$ and Claire L. Shovlin ${ }^{1,5^{*}}$
}

\begin{abstract}
Hereditary hemorrhagic telangiectasia (HHT) poses substantial burdens due to nosebleeds and iron deficiency resulting from recurrent hemorrhagic iron losses. Recent studies by our group found surprising links between HHT nosebleeds and certain food groups. In this letter, we report 7-day weighed food diary assessments of an unselected group of 25 UK patients with HHT whose nosebleeds ranged from mild to severe (median epistaxis severity score 4.66 , range $0.89-9.11$ ). The diaries provide evidence that food items most commonly reported to provoke nosebleeds were ingested by fewer HHT patients, compared to food items less commonly reported to provoke nosebleeds (chi-squared $p<0.001$ ).
\end{abstract}

Keywords: Anemia, Epistaxis, Fish oil, Hemorrhage adjusted iron requirement (HAIR), Iron, 7-day weighed food diary

\section{Introduction}

Nosebleeds (epistaxis) occur very frequently in patients with hereditary hemorrhagic telangiectasia (HHT) and significantly impact on quality of life. Typically, nosebleeds severity varies over time, and nosebleeds often come in clusters. Most HHT patients experience nosebleeds at least once a week, and in many series, more than a third experience them on a daily or near-daily basis [1, 2]. In one survey, 326/666 (49\%) of unselected respondents with HHT had required specialist invasive treatments, often requiring multi-modality therapy [1]. Through under-replacement of hemorrhagic iron losses, nosebleeds commonly result in iron deficiency anemia, regular use of iron tablets, and in as many as 30\% of cases, multiple iron infusions or blood transfusions [3].

Nosebleeds result from the presence of abnormal nasal vasculature, and are the usual primary outcome measure in clinical trials of new HHT therapeutic agents. In two large international surveys by our group, multiple dietary

\footnotetext{
* Correspondence: c.shovlin@imperial.ac.uk

${ }^{1}$ National Heart and Lung Institute Cardiovascular Sciences, Imperial College London, London, UK

${ }^{5}$ Respiratory Medicine, Imperial College Healthcare NHS Trust, London, UK Full list of author information is available at the end of the article
}

items were reported to exacerbate HHT nosebleeds $[1,2]$. Here we report data that suggests some HHT patients may spontaneously modify their diet to avoid food items perceived to provoke nosebleeds.

\section{Methods and results}

In 2011, with ethical approval from the London Wandsworth Research Ethics Committee (11/H0803/8), and written informed consent obtained from all participants, an unselected group of $25 \mathrm{HHT}$ patients measured their food intake using a 7-day weighed food diary [4]. Participants were encouraged to follow their normal diet, recording the time, the food or drink consumed, a description of the brand name, and the method of preparation, in addition to the weighed amount in grams, for each different item consumed. Nosebleeds were quantified using the epistaxis severity score which has a maximum score of 10 [5].

From 2012, with ethical approval from the NRES Committee East Midlands-Derby 1 Research Ethics Committee, and online informed consent obtained from all participants, we performed unbiased evaluations of nosebleeds by surveying HHT patients [1,2]. Following spontaneous reports of dietary nosebleed precipitants [1], our subsequent survey [2] directed participants to 
18 different food groups where they were offered tick boxes of i) "This is not part of my diet", ii)"I have not noticed any difference", iii)"Seem to bring on nosebleeds", iv) "Seem to help nosebleeds". In total, 37/265 (14.0\%) participants reported that chocolate seemed to bring on their nosebleeds, with strawberries $(25 / 260$, $9.6 \%)$ and citrus fruits $(21 / 262,8.0 \%)$ the next most commonly reported food groups (Table 1 ). These findings mirrored those of the earlier survey [1].

In the 7-day weighed food diary cohort, the epistaxis severity score ranged from 0.89 to 9.11 (median 4.66). When we evaluated the food items ingested by the 25 participants, we noted that the least frequently ingested foods comprised beans/lentils, chocolate, citrus fruits, savory biscuits, strawberries/other berries, and sweets (Table 1). Thus, the food items most commonly reported to precipitate nosebleeds by the HHT Survey respondents (chocolate, strawberries and citrus fruits) were ingested by fewer HHT-affected participants in the weighed food diary assessment (Table 1).

For statistical analyses, all of the foods in the respective tertile were pooled into least consumed, midand most consumed foods across all study participants. The least ingested tertile foods were reported to precipitate nosebleeds in 108/1542 cases (7.0\%) compared to $49 / 1501$ (3.2\%) for the mid tertile and $52 / 1575$ (3.3\%) for the most ingested foods $(p<0.001$ by chisquared test.)

\section{Conclusion}

This is clearly a small study that should be repeated in larger HHT cohorts, and is additionally unable to address potential impacts of portions sizes, food-nosebleed intervals, and other secondary questions that will need to be foci of future studies. Nonetheless, the current study does appear to provide evidence that HHT patients may modify their diet to avoid food items perceived to provoke nosebleeds. We recognise that diet is an important component of people's lifestyle, and that suggesting restrictions may not be acceptable to many people with HHT. Dietary modification should be a matter for patient choice, and not over-emphasised by clinicians, unless this negatively impacts on nutrient intake. However if nosebleeds have significant impact on patients' lifestyle and general health then there is an argument that nosebleed-related dietary advice could be part of clinical management. The current observations may offer acceptable opportunities for some people to better control nosebleeds, in addition to improving future HHT nosebleed clinical trial design.

Table 1 Details of the 1,523 portions of food ingested by the 25 food diary study participants, and reports of nosebleed effects in the 2013 HHT Survey

\begin{tabular}{|c|c|c|c|c|c|c|c|c|}
\hline \multirow[b]{3}{*}{ Category } & \multirow{2}{*}{\multicolumn{3}{|c|}{2011 7-day weighed food diary }} & \multicolumn{5}{|c|}{2013 HHT Survey on Nosebleeds } \\
\hline & & & & \multirow{2}{*}{$\begin{array}{l}\text { Total reports } \\
\text { Number } \\
\text { ingesting }\end{array}$} & \multicolumn{2}{|c|}{$\begin{array}{l}\text { Food item seemed to } \\
\text { bring on nosebleeds }\end{array}$} & \multicolumn{2}{|c|}{$\begin{array}{l}\text { Food item seemed } \\
\text { to help nosebleeds }\end{array}$} \\
\hline & $\begin{array}{l}\text { Number } \\
\text { ingesting }\end{array}$ & $\begin{array}{l}\text { Total } \\
\text { Portions } \\
\end{array}$ & $\begin{array}{l}\text { Tertile of } \\
\text { ingestion }\end{array}$ & & $\begin{array}{l}\text { Number } \\
\text { reporting }\end{array}$ & $\%$ & $\begin{array}{l}\text { Number } \\
\text { reporting }\end{array}$ & $\%$ \\
\hline Sweets & 6 & 21 & 1 & 259 & 18 & 6.95 & 0 & 0.00 \\
\hline Strawberries/other berries & 10 & 24 & 1 & 260 & 25 & 9.62 & 5 & 1.92 \\
\hline Beans and lentils & 11 & 16 & 1 & 258 & 2 & 0.78 & 4 & 1.55 \\
\hline Savory biscuits & 13 & 21 & 1 & 238 & 5 & 2.10 & 0 & 0.00 \\
\hline Citrus fruits & 13 & 48 & 1 & 262 & 21 & 8.02 & 2 & 0.76 \\
\hline Chocolate & 14 & 29 & 1 & 265 & 37 & 13.96 & 1 & 0.38 \\
\hline Crisps & 15 & 45 & 2 & 242 & 2 & 0.83 & 0 & 0.00 \\
\hline Bananas, melons & 16 & 56 & 2 & 260 & 9 & 3.46 & 3 & 1.15 \\
\hline Sweet biscuits & 19 & 59 & 2 & 243 & 7 & 2.88 & 0 & 0.00 \\
\hline Fast or frozen foods & 21 & 57 & 2 & 240 & 9 & 3.75 & 2 & 0.83 \\
\hline Breakfast cereals & 22 & 126 & 2 & 253 & 5 & 1.98 & 0 & 0.00 \\
\hline Cheese & 22 & 66 & 2 & 263 & 17 & 6.46 & 0 & 0.00 \\
\hline Meat or fish & 24 & 148 & 3 & 259 & 13 & 5.02 & 6 & 2.32 \\
\hline Green vegetables & 24 & 122 & 3 & 268 & 6 & 2.24 & 10 & 3.73 \\
\hline Other vegetables & 24 & 153 & 3 & 264 & 10 & 3.79 & 4 & 1.52 \\
\hline Bread & 25 & 166 & 3 & 260 & 7 & 2.69 & 1 & 0.38 \\
\hline Potatoes, rice and pasta & 25 & 84 & 3 & 262 & 5 & 1.91 & 0 & 0.00 \\
\hline Milk/yoghurt/butter & 25 & 179 & 3 & 262 & 11 & 4.20 & 3 & 1.15 \\
\hline
\end{tabular}




\section{Abbreviations}

ESS: Epistaxis severity score; HAIR: Hemorrhage adjusted iron requirement; HHT: Hereditary hemorrhagic telangiectasia

\section{Acknowledgements}

We thank the patients for their willing participation in these studies.

\section{Funding}

This study received support from Imperial College London's BSc Project Funds (for MS), King's College London (for HF), and donations from families and friends of HHT patients. Dr Shovlin also acknowledges support from the $\mathrm{NIHR}$ Biomedical Research Centre Funding Scheme (Imperial BRC). The funders played no role in the design and conduct of the study; collection, management.

\section{Availability of data and materials}

The datasets from the current study are available from the corresponding author on reasonable request.

\section{Authors' contributions}

HF contributed to study design, recruited patients for the 7-day weighed food diaries, performed data analysis and interpretation, and drafted methodological sections. MS performed data interpretation. $\mathrm{MH}$ contributed to study design, and advised on dietary concepts. KW contributed to study design, advised on dietary concepts and co-supervised HF. CLS conceived the study; participated in study design, supervised HF and MS, performed the statistical analysis; generated the Figures; and wrote the final manuscript. All authors read and approved the final manuscript.

\section{Competing interests}

The authors have no competing interests to declare.

\section{Consent for publication}

Not applicable.

\section{Ethics approval and consent to participate}

The 7 day weighed food diary study received ethical approval from the London Wandsworth Research Ethics Committee (11/H0803/8). All participants provided written informed consent. The HHT nosebleed survey received ethical approval from the NRES Committee East Midlands-Derby 1 Research Ethics Committee (12/EM/0073). All participants provided online informed consent.

\section{Author details}

${ }^{1}$ National Heart and Lung Institute Cardiovascular Sciences, Imperial College London, London, UK. ${ }^{2}$ Imperial College School of Medicine, Imperial College London, London, UK. ${ }^{3}$ Diabetes and Nutritional Sciences Division, King's College London, London, UK. ${ }^{4}$ Nutrition and Dietetics, Plymouth University, Plymouth, UK. ${ }^{5}$ Respiratory Medicine, Imperial College Healthcare NHS Trust, London, UK.

Received: 1 October 2016 Accepted: 20 January 2017

Published online: 28 March 2017

\section{References}

1. Silva BM, Hosman AE, Devlin HL, Shovlin CL. Lifestyle and dietary influences on nosebleed severity in hereditary hemorrhagic telangiectasia. Laryngoscope. 2013;123(5):1092-9.

2. Elphick A, Shovlin CL. Relationships between epistaxis, migraines, and triggers in hereditary hemorrhagic telangiectasia. Laryngoscope. 2014; 124(7):1521-8.

3. Finnamore H, Le Couteur J, Hickson M, Busbridge M, Whelan K, Shovlin CL. Hemorrhage-adjusted iron requirements, hematinics and hepcidin define hereditary haemorrhagic telangiectasia as a model of hemorrhagic iron deficiency. PLoS One. 2013;8(10):e76516.

4. Finnamore HE, Whelan $\mathrm{K}$, Hickson M, Shovlin CL. Top dietary iron sources in the UK. Br J Gen Pract. 2014;64(621):172-3.

5. Hoag JB, Terry P, Mitchell S, Reh D, Merlo CA. An epistaxis severity score for hereditary hemorrhagic telangiectasia. Laryngoscope. 2010;120(4):838-43.

\section{Submit your next manuscript to BioMed Central and we will help you at every step:}

- We accept pre-submission inquiries

- Our selector tool helps you to find the most relevant journal

- We provide round the clock customer support

- Convenient online submission

- Thorough peer review

- Inclusion in PubMed and all major indexing services

- Maximum visibility for your research

Submit your manuscript at www.biomedcentral.com/submit 